\title{
Ion Exchange Adsorption Kinetics of Miglitol by D001 Resins
}

\author{
Jiebing Zhang1 ${ }^{*}$, Xiubin Ren1, Guangheng Wang1, Xiaoli Zhang ${ }^{2}$ \\ ${ }^{1}$ College of Chemistry and Chemical Engineering, Xi'an University of Science and Technology, Xi'an, China \\ ${ }^{2}$ College of Chemical Engineering, Northwest University, Xi'an, China \\ Email: *delierson@163.com
}

How to cite this paper: Zhang, J.B., Ren, X.B., Wang, G.H. and Zhang, X.L. (2017) Ion Exchange Adsorption Kinetics of Miglitol by D001 Resins. Advances in Chemical Engineering and Science, 7, 420-438. https://doi.org/10.4236/aces.2017.74030

Received: June 28, 2017

Accepted: October 16, 2017

Published: October 19, 2017

Copyright (c) 2017 by authors and Scientific Research Publishing Inc. This work is licensed under the Creative Commons Attribution International License (CC BY 4.0).

http://creativecommons.org/licenses/by/4.0/

cC) (†) Open Access

\begin{abstract}
In order to explore internal factors for adsorption kinetic effect of miglitol by D001 resin, a batch adsorption operation for miglitol kinetic adsorption at different concentrations, temperatures and vibrating rates was investigated in oscillator (SHZ-A), respectively. The different kinetic mathematical model, Webber-Morris kinetic equation, film diffusion coefficient equation and kinetic boundary model were all applied to discuss the adsorption process. The results showed that Type 1 pseudo-second order kinetic equation can be all used to describe miglitol adsorbed by D001 resin at different concentrations, temperatures and vibrating rates. Moreover, the total activation energy (Ea) can be calculated and its value is $9.7 \mathrm{~kJ} / \mathrm{mol}$, and then calculated values of the process film diffusion coefficient and pore diffusion coefficient, it may be inferred from these gotten values that the ion exchange process is all mainly controlled by film diffusion. Therefore, the results also suggest that the external adsorption factors such as solute concentration, temperature and vibrating rate for effect of mass transfer diffusion process control of miglitol onto D001 resin are relatively weak.
\end{abstract}

\section{Keywords}

Miglitol, Ion Exchange Adsorption, Kinetic Equation, Resins

\section{Introduction}

Miglitol ((2R, 3R, 4R, 5S)-1-(2-hydroxyethyl)-2-(hydroxymethyl) piperidine3,4,5-triol, CAS No.72432-03-2) is a desoxynojirimycin derivative, also competitively inhibits glucoamylase and sucrase but has weak effects on pancreatic $\alpha$-amylase, it is the first pseudomonosaccharide $\alpha$-glucosidase inhibitor, smooths postprandial peak plasma glucose levels and thus can improve glycaemic control, 
Miglitol is generally well tolerated and is not associated with bodyweight gain or hypoglycaemia as monotherapy. Meanwhile, the drug is also systemically absorbed and not metabolised, also is rapidly excreted via the kidneys [1] [2] [3]. It was firstly developed by Bayer as drug for the treatment of type II (non-insulin-dependent) diabetes mellitus. Miglitol was authorized for marketing in Europe (trade name: Diastabol ${ }^{\circledR}$ ), the United States (Glyset ${ }^{\oplus}$ ) and in China, miglitol was also known as Otianpin ${ }^{\circledR}$ [4]. Nowadays, miglitol can be synthesized via different many ways, mainly including two types of chemical synthesis and chemical-biological synthesis. However, due to its many synthetic steps, complex craft and higher production cost for most of the chemical synthetic miglitol method, and it has been gradually replaced by chemical-biological method [5] [6] The chemical-biological synthesis is still regarded as the more efficient industrial process. The reaction process is consisted of three-step synthesis, i.e. regioselective microbial oxidation and two step simple chemical reductive reactions. Two intermediates that containing amino group were formed in the process, i.e. $\mathrm{N}$-hydroxyethyl-1-amino-1-deoxy-D-sorbitol and its corresponding L-sorbose derivative [7] [8]. As known that the synthesis substance generally possesses the higher purity product for the premise of the pharmaceutical application. As a rule, the synthesized miglitol is expected to establish the separation method of reaction mixture to remove the intermediates and other related compounds, and reaches the purpose of miglitol purification.

As known that adsorption of cation ion exchange resin is a suitable technology for the separation of N-substituted-1-desoxynojirimycin and miglitol [9] [10]. In our experiment, D001 resin as a separation medium has been appeared a good adsorption efficiency. That is a macroreticular strong-acidic cation ion exchange resin and applies widely in China. Up to now, due to the theory lack for miglitol separation, especially adsorption kinetics, the results of adsorption kinetics can conduct separation craft of substance and infer the efficiency of adsorption or separation for mixture. Therefore, it is very important to purify miglitol. In this study, the miglitol adsorption kinetics at different effect factors will be investigated by the selected D001 resin as adsorbent in batch adsorption, our results are not only for important scientific significance but also for wide reference in practical application.

\section{Materials and Methods}

\subsection{Materials}

The D001 resin $\left(\mathrm{Na}^{+}\right.$form) was purchased from Sunresin Technol. Ltd., Xi'an, China. The chemical and physical properties of the resin are similar to those of Amberlite IR200 resins [11]. Drug-grade miglitol was obtained from Jinan Huifengda Chemical Ltd., Ji'nan, China. $\mathrm{KMnO}_{4}$ and $\mathrm{NaOH}$ were used to aid the content determination of miglitol, and all other reagents in the experiment were of analytical grade. The constant temperature bath oscillator (SHZ-A) was used for adsorption process studies, The content of miglitol was determined at 610 
$\mathrm{nm}$ by the double-beam UV-Vis spectrophotometer (TU-1900) [12]. The raw material was weighed by Electronic Analytical Balance (FA2004N).

\subsection{Adsorption Kinetics Experiments}

Fixed $200 \mathrm{mg}$ resin into the different conical flasks $(250 \mathrm{~mL})$, miglitol was diluted by the distilled water and formed experimental set concentration solution. The adsorption process factors of different concentrations $(4 \mathrm{mmol} / \mathrm{L}, 6 \mathrm{mmol} / \mathrm{L}$, $8 \mathrm{mmol} / \mathrm{L})$, different temperatures $\left(30^{\circ} \mathrm{C}, 40^{\circ} \mathrm{C}, 50^{\circ} \mathrm{C}\right)$ and different vibrating rates (80 rmp, $120 \mathrm{rmp}, 160 \mathrm{rmp}$ ) were investigated in batch adsorption experiment, respectively. The adsorbed solutions were taken $1 \mathrm{~mL}$ by pipette at different time intervals and were measured by spectrophotometer at $610 \mathrm{~nm}$. The process adsorption capacity at time t by D001 resins was as follows:

$$
q_{t}=\frac{C_{0} V_{0}-\left[C_{n} V_{n}+\sum_{i=1}^{n-1} C_{i} V_{i}\right]}{W}
$$

where $q_{t}(\mathrm{mmol} / \mathrm{g})$ is the adsorption capacity of resin at time $t, C_{0}(\mathrm{mmol} / \mathrm{L})$ and $V_{0}(\mathrm{~L})$ are the initial concentration and volume of miglitol solution, $C_{n}(\mathrm{mmol} / \mathrm{L})$ and $V_{n}(\mathrm{~L})$ are the concentration and volume of remaining miglitol solution at time $n, C_{i}(\mathrm{mmol} / \mathrm{L})$ and $V_{i}(\mathrm{~L})$ correspond with the substance concentration and volume of the taken solution sample at time $i, W$ is the weight of resin.

\subsection{Batch Adsorption Kinetic Theoretical Background}

\subsubsection{The Pseudo-First Order Equation}

The pseudo-first order equation for solid-liquid adsorption system was firstly proposed by Lagergren in 1989 [13]. The equation mathematical expression is given [14]:

$$
\frac{\mathrm{d} q_{t}}{\mathrm{~d} t}=k_{1}\left(q_{e}-q_{t}\right)
$$

where $q_{e}(\mathrm{mmol} / \mathrm{g})$ is the amount of adsorbate adsorbed at equilibrium, $q_{t}$ $(\mathrm{mmol} / \mathrm{g})$ is the amount of adsorbate adsorbed at time $t . \quad k_{1} \quad(\mathrm{~g} / \mathrm{mmol} \cdot \mathrm{h})$ is rate constant for the Lagergren equation. Integrating Equation (2) with the following boundary condition:

1) $t=0, q_{t}=0$

2) $t=t, q_{t}=q_{t}$

The linear equation is obtained:

$$
\log \left(q_{e}-q_{t}\right)=\log q_{e}-\frac{k_{1} t}{2.303}
$$

If $t \rightarrow 0$, the initial rate (h1) is [15]:

$$
h_{1}=k_{1} q_{e}
$$

As $k_{1}\left(q_{e}-q_{t}\right)$ cannot stand for total active site of adsorbent, and at the same time $\log q_{e}$ in Equation (3) is the adjustable parameter and often finds that its value is not equal to intercept value by linear regression with $\log \left(q_{e}-q_{t}\right)$ and 
$t$. The values of $\log q_{e}$ must be intercept value if the equation is the first-order kinetic equation. Therefore, in order to distinguish the first-order equation, and the above Lagergren equation is also called the pseudo-first order equation. The pseudo-first order equation can only be used for estimating rate constant $k_{1}$ and not estimate $q_{e}$ value.

\subsubsection{The Pseudo-Second Order Equation}

The pseudo-second order equation was firstly proposed by Ho and McKay [16] [17]. The pseudo-second order equation can be derived from chemical equations. The equation can be used for estimating $q_{e}$ value. Its general mathematical expression is as follows:

$$
\frac{\mathrm{d} q_{t}}{\mathrm{~d} t}=k_{2}\left(q_{e}-q_{t}\right)^{2}
$$

where $k_{2}\left(\mathrm{~g}^{2} / \mathrm{mmol}^{2} \cdot \mathrm{h}\right)$ is rate constant for the pseudo-second order equation.

Integrating Equation (5) with the following boundary condition:

1) $t=0, q_{t}=0$

2) $t=t, q_{t}=q_{t}$

The following equation can be gotten:

$$
\frac{t}{q_{t}}=\frac{1}{k_{2} q_{e}^{2}}+\frac{t}{q_{e}}
$$

If $\mathrm{t} \rightarrow 0$, the initial rate $\left(h_{2}\right)$ is

$$
h_{2}=k_{2} q_{e}^{2}
$$

The Equation (7) is substituted into Equation (6) and obtains Type 1 pseudo-second order equation, the equation can be written as:

$$
\frac{t}{q_{t}}=\frac{1}{h_{2}}+\frac{t}{q_{e}}
$$

By means of linear fitting with $\frac{t}{q_{t}}$ and $t$, the gotten results may use for calculating values of $q_{e}$ and $k_{2}$, respectively.

In addition, the above pseudo-second order equation can also transform other four types of pseudo-second order equation by a series of transformation. These equations are separately as follows:

The Type 2 pseudo-second order equation is:

$$
\frac{1}{q_{t}}=\frac{1}{h_{2} t}+\frac{1}{q_{e}}
$$

The Type 3 pseudo-second order equation is:

$$
\frac{1}{t}=\frac{h_{2}}{q_{t}}-\frac{h_{2}}{q_{e}}
$$

The Type 4 pseudo-second order equation is:

$$
\frac{q_{t}}{t}=h_{2}-\frac{h_{2}}{q_{e}} q_{t}
$$


The Type 5 pseudo-second order equation is:

$$
\frac{1}{\left(q_{e}-q_{t}\right)}=\frac{1}{q_{e}}+k_{2} t
$$

\subsubsection{The Elovish Equation}

The Elovish equation was generally applied to chemisorption kinetic analysis [18], and it was established by changes of adsorption capacity. The mathematical equation is expressed as:

$$
\frac{\mathrm{d} q_{t}}{\mathrm{~d} t}=\alpha \exp \left(-\beta q_{t}\right)
$$

where $\alpha(\mathrm{mmol} / \mathrm{g} \cdot \mathrm{h})$ is initial adsorption rate, $\beta(\mathrm{g} / \mathrm{mmol})$ is desorption constant. As far as chemical adsorption is concerned, the $\beta$ value is relate to adsorption activation energy and covering content of adsorbate onto adsorbent surface.

By assuming $\alpha \beta t \gg 1$, and Integrating Equation (13) with the following boundary condition:

1) $t=0, q_{\mathrm{t}}=0$

2) $t=t, q_{t}=q_{t}$

The above Equation (13) can be transformed into the following equation:

$$
q_{t}=\frac{1}{\beta} \ln (\alpha \beta)+\frac{1}{\beta} \ln t
$$

The kinetic constant values of $\alpha$ and $\beta$ can be estimated by linear fitting with $q_{t}$ and $t$.

\subsubsection{Mass Transfer Mechanism}

As far as ion exchange adsorption process is concerned, it is very important to understand transfer direction and transfer rate of adsorbate for exploring mass transfer mechanism during adsorption process. The kinetic boundary model is widely applied to judge control step of mass transfer rate [19] [20]. The mass transfer process is divided into film diffusion, particle pore diffusion and chemical reaction according to mass transfer process, and the corresponding mathematical equations are established. These equations are as follows:

Film diffusion: $\ln (1-F)=-k t$

Particle pore diffusion: $1-3(1-F)^{2 / 3}+2(1-F)=k t$

Chemical reaction: $1-(1-F)^{1 / 3}=k t$

There into, $k$ is mass transfer rate constant, $F$ is called ion exchange degree, the corresponding equation is written as:

$$
F=\frac{C_{0}-C_{t}}{C_{0}-C_{e}}
$$

The established relationship between $F$ and $t$ from the kinetic boundary model may be used to judge main mass transfer process by correlation coefficient $\left(R^{2}\right)$ 
during ion exchange. The main mass transfer process corresponds with the slowest diffusion, and its process means the largest mass transfer resistance.

Meanwhile, there are different mass transfer rate constants with at different experimental temperatures. The corresponding activation energy $\left(E_{a}\right)$ can be calculated by Arrhenius equation [21]. Its mathematical equation is:

$$
k=A \exp \left(-E_{a} / R T\right)
$$

where $R$ is a ideal gas constant, $A$ is a constant. Equation (19) can be rewritten to a linear form from which the activation energy can be calculated from the slope, the equation expression is:

$$
\ln k=-\frac{E_{a}}{R T}+\ln A
$$

The calculated value of $E_{a}$ can also be used to determine ion exchange control step [22]. The ion exchange process is controlled by film diffusion at $E_{a}<16.0$ $\mathrm{kJ} / \mathrm{mol}$. It is for particle pore diffusion at $21.0 \mathrm{~kJ} / \mathrm{mol}<E_{a}<38.0 \mathrm{~kJ} / \mathrm{mol}$, and at $E_{a}>50.0 \mathrm{~kJ} / \mathrm{mol}$, it belongs to chemical reaction control.

In addition, the activation entropy change value $\left(\Delta S^{*}\right)$ can be estimated by the following equation and the calculated value $A$ by the above Arrhenius equation. The equation is defined as [23]:

$$
A=\left(\frac{2.72 d^{2} K T}{h}\right) \exp \left(\frac{\Delta S^{*}}{R}\right)
$$

where $K\left(1.38 \times 10^{-23} \mathrm{~J} / \mathrm{K}\right)$ is Boltzmann constant, $h\left(6.62 \times 10^{-34}\right)$ is Plank constant. $d$ is for the average distance of the ion exchange active site, and its value is generally taken as $5 \times 10^{-10} \mathrm{~m}, T$ is absolute zero degree, its value is set to $273 \mathrm{~K}$.

\section{Results and Discussion}

\subsection{Effect of Concentrations}

The ion exchange process at different initial concentrations of miglitol solution onto resin D001 resin was investigated and was analysized by the kinetic adsorption mathematical models, and the results are shown in Figures 1-3. At the same time, the parameters are got by kinetic equation fitting and are given in Table 1. Comparing with Figures 1-3, and it shows that the ion exchange process is fitted better by Type 1 pseudo-second order kinetic equation. The experimental parameters from Table 1 is further showed that the correlation coefficients are gotten from fitting pseudo-first order kinetic equation and pseudo-second order kinetic equation, and these values reach over 0.99 . The parameters for $k_{1}$ and $h_{1}$ increase with enhancing the initial concentration solution of miglitol, and their change trends are closely related to the value of initial solution concentration and concentration difference between solution adsorbate and absorbent surface. Meanwhile, Table 1 is also found that the experimental equilibrium adsorption capacity $\left(q_{e, \text { exp }}\right)$ is not equal to the theoretical adsorption capacity $\left(q_{e, \text { exp }}\right)$ gotten from pseudo-first order kinetic equation. The result further proves the ion exchange process is not adapted to first-order kinetic equation. In addition, the 


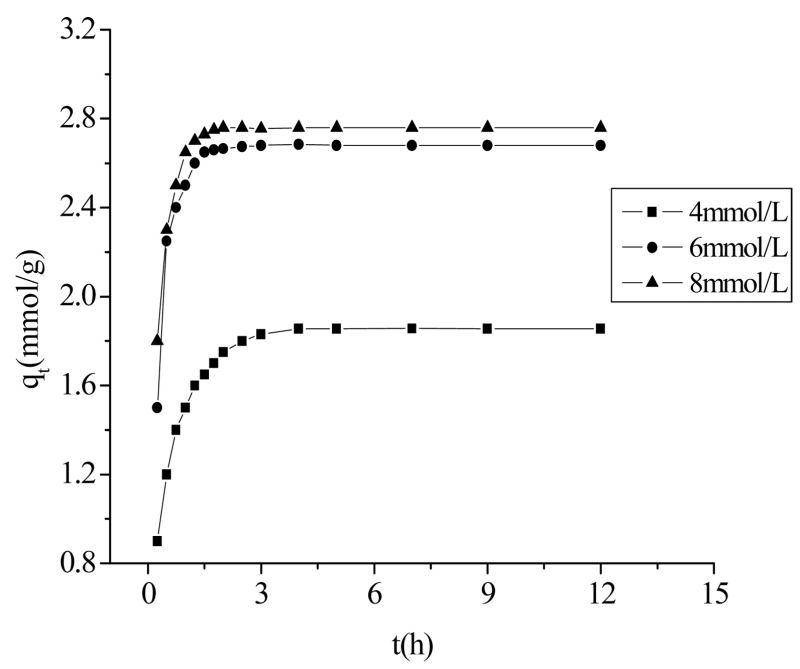

Figure 1. Dynamic process of miglitol at different concentrations adsorbed onto resin D001.

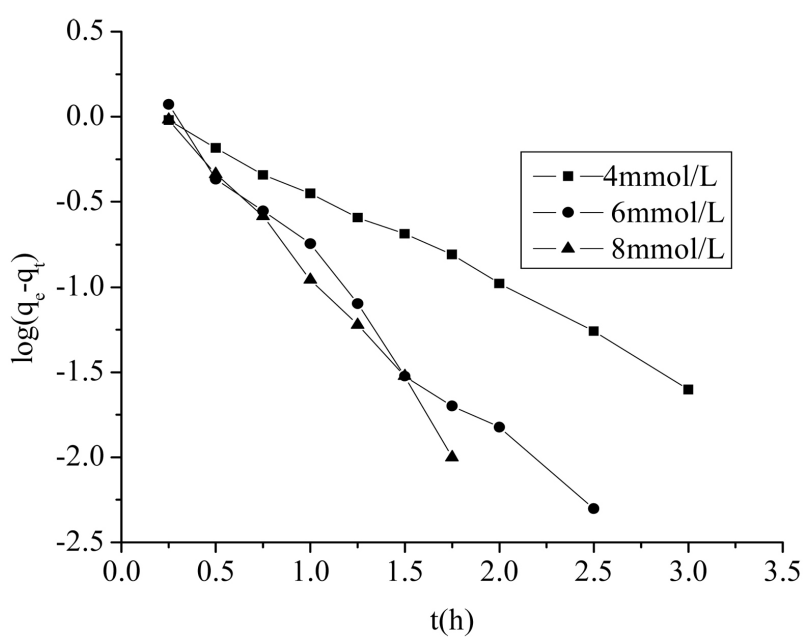

Figure 2. Fitting curves of the pseudo-first order kinetic model for miglitol adsorbed onto D001 resin.

parameter values of $k_{2}$ and $h_{2}$ were calculated by Type 1 pseudo-second order kinetic equation vary with the same change trend for values of $k_{1}$ and $h_{1}$ in Table 1 , their change trend is connected with the higher correlation coefficient gotten by the above two equations. In the meantime, the minimum difference between values of $q_{e, c a l}$ and $q_{e, \text { exp }}$ is showed from Table 1, and it suggests that the ion exchange process can be described by Type 1 pseudo-second order kinetic equation. Moreover, as known that the pseudo-second order kinetic model corresponds with 5 mathematical equation types. Nevertheless, the results find that the parameter values and correlation coefficients gotten by these equations differs each other. It showed that different analysis method for ion exchange experimental data can be directly influenced with different type of pseudo-second order kinetic equation. It is very important to select an appropriate type of pseudo-second order kinetic equation for describing ion exchange process. 


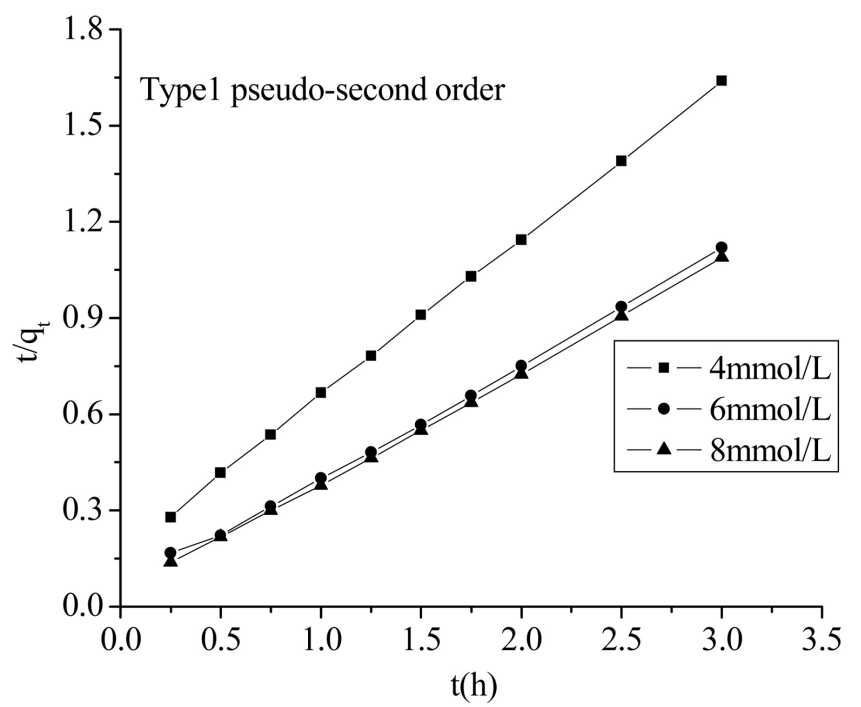

(a)

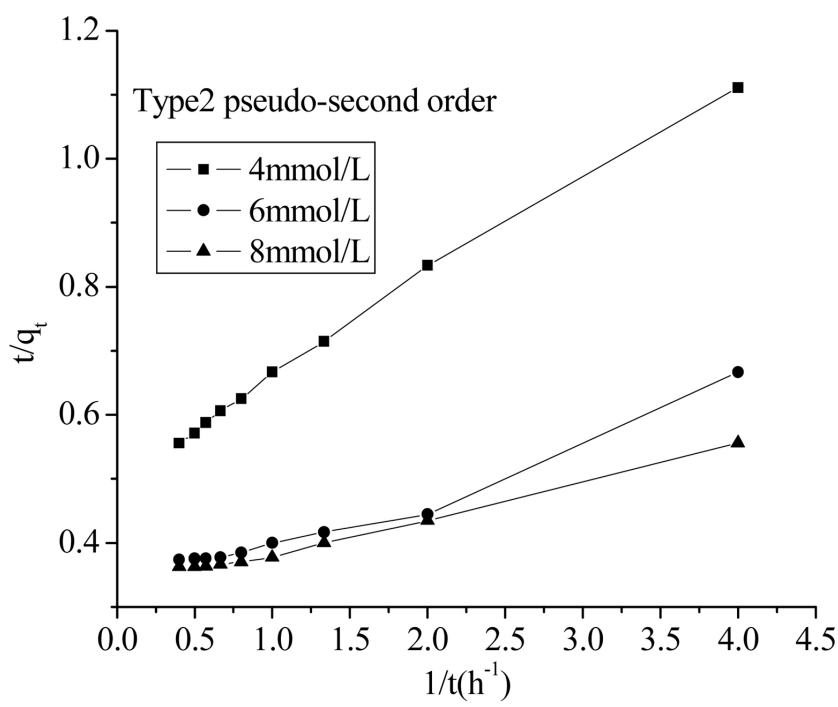

(b)

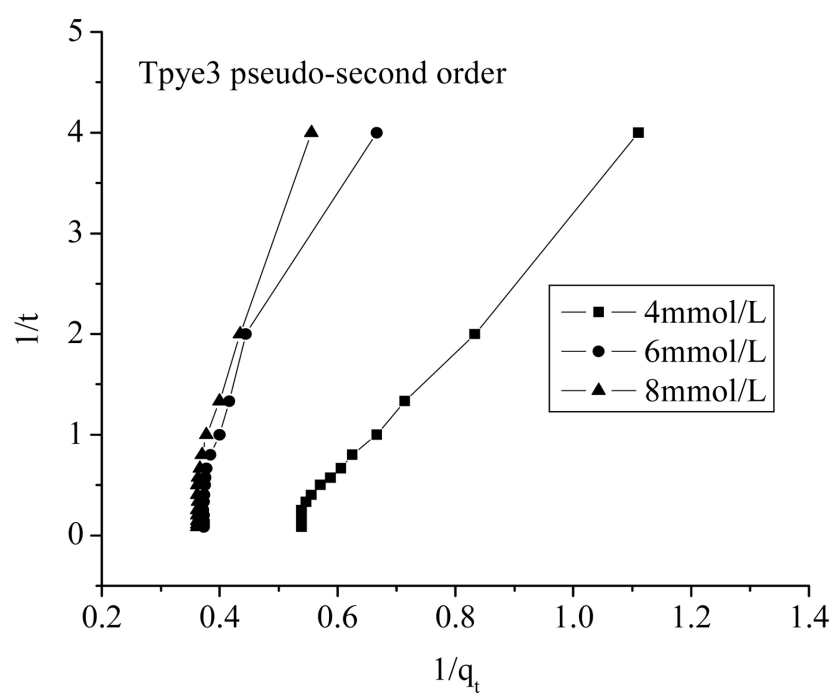

(c) 


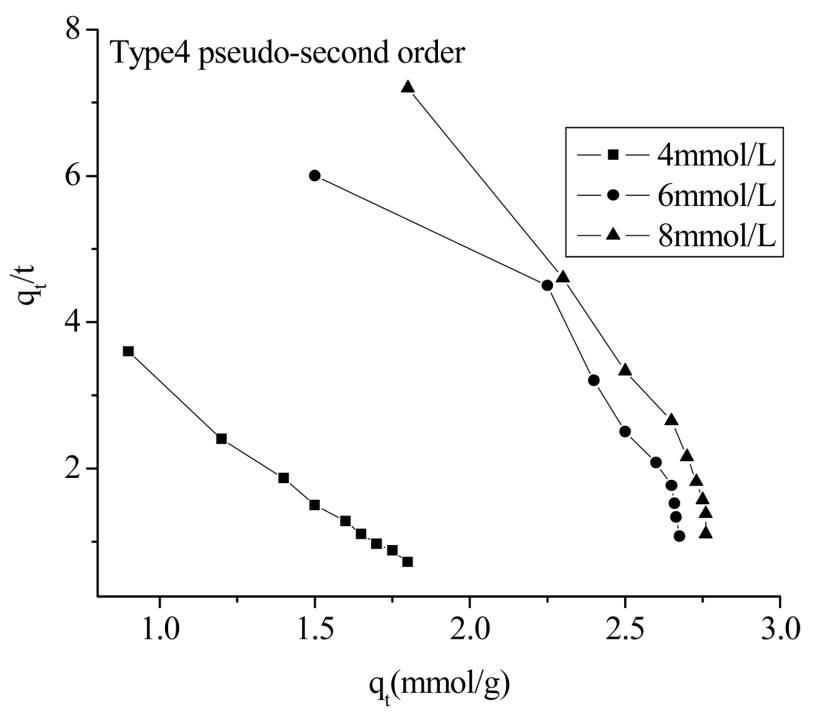

(d)



(e)

Figure 3. Fitting curves of the pseudo-second-order kinetic model for miglitol adsorbed onto D001 resin.

On the other hand, the ion exchange behavior is discussed at different initial concentrations for miglitol solution onto D001 resin by Webber-Morris particle pore diffusion model [24] [25]. It may be used to infer whether the mass transfer process is a internal pore diffusion process or not. The Webber-Morris pore diffusion mathematical equation is:

$$
q_{t}=k_{i d} t^{0.5}+C
$$

where $k_{\text {id }}\left(\mathrm{mmol} / \mathrm{g} \cdot \mathrm{min}^{0.5}\right)$ is internal diffusion rate constant. $C$ is an intercept of the equation, its value is related to the boundary layer thickness of particle, the external mass transfer resistance is directly proportional to the size of the value.

Supposing substance diffusion process is only controlled by particle internal pore diffusion, at this time, the relationship between $q_{t}$ and $t^{0.5}$ can present 
Table 1. Kinetic fitting results of miglitol adsorbed onto D001 resin.

\begin{tabular}{|c|c|c|c|c|}
\hline \multirow{2}{*}{ Kinetic models } & \multirow{2}{*}{ Parameters } & \multicolumn{3}{|c|}{$C_{0}(\mathrm{mmol} / \mathrm{L})$} \\
\hline & & 4 & 6 & 8 \\
\hline \multirow[b]{2}{*}{ Pseudo-first order: } & $q_{e, \exp }(\mathrm{mmol} / \mathrm{g})$ & 1.86 & 2.68 & 2.76 \\
\hline & $q_{e, c a l}(\mathrm{mmol} / \mathrm{g})$ & 1.29 & 1.69 & 2.13 \\
\hline \multirow{3}{*}{$\log \left(q_{e}-q_{t}\right)=\log q_{e}-\frac{k_{1} t}{2.303}$} & $k_{1}(\mathrm{~g} / \mathrm{mmol} \cdot \mathrm{h})$ & 1.28 & 2.42 & 2.95 \\
\hline & $h_{1}(1 / \mathrm{h})$ & 1.64 & 4.09 & 6.28 \\
\hline & $R^{2}$ & 0.9980 & 0.9925 & 0.9967 \\
\hline \multirow{5}{*}{$\begin{array}{l}\text { Type-1 pseudo-second-order: } \\
\qquad \frac{t}{q_{t}}=\frac{1}{h_{2}}+\frac{t}{q_{e}}\end{array}$} & $q_{e, \exp }(\mathrm{mmol} / \mathrm{g})$ & 1.86 & 2.68 & 2.76 \\
\hline & $q_{e, c a l}(\mathrm{mmol} / \mathrm{g})$ & 1.90 & 2.70 & 2.78 \\
\hline & $k_{2}\left(\mathrm{~g}^{2} / \mathrm{mmol}^{2} \cdot \mathrm{h}\right)$ & 2.48 & 5.49 & 7.05 \\
\hline & $h_{2}(1 / \mathrm{h})$ & 8.97 & 40.00 & 54.50 \\
\hline & $R^{2}$ & 0.9998 & 0.9999 & 0.9999 \\
\hline \multirow{5}{*}{$\begin{array}{l}\text { Type } 2 \text { pseudo-second-order: } \\
\qquad \frac{1}{q_{t}}=\frac{1}{h_{2} t}+\frac{1}{q_{e}}\end{array}$} & $q_{e, \exp }(\mathrm{mmol} / \mathrm{g})$ & 1.86 & 2.68 & 2.76 \\
\hline & $q_{e, c a l}(\mathrm{mmol} / \mathrm{g})$ & 2.00 & 2.94 & 2.94 \\
\hline & $k_{2}\left(\mathrm{~g}^{2} / \mathrm{mmol}^{2} \cdot \mathrm{h}\right)$ & 1.67 & 1.66 & 2.36 \\
\hline & $h_{2}(1 / \mathrm{h})$ & 6.67 & 14.32 & 20.45 \\
\hline & $R^{2}$ & 0.9974 & 0.9606 & 0.9778 \\
\hline \multirow{5}{*}{$\begin{array}{l}\text { Type } 3 \text { pseudo-second-order: } \\
\qquad \frac{1}{t}=\frac{h_{2}}{q_{t}}-\frac{h_{2}}{q_{e}}\end{array}$} & $q_{e, \exp }(\mathrm{mmol} / \mathrm{g})$ & 1.86 & 2.68 & 2.76 \\
\hline & $q_{e, c a l}(\mathrm{mmol} / \mathrm{g})$ & 1.97 & 2.95 & 2.92 \\
\hline & $k_{2}\left(\mathrm{~g}^{2} / \mathrm{mmol}^{2} \cdot \mathrm{h}\right)$ & 1.68 & 1.49 & 2.28 \\
\hline & $h_{2}(1 / \mathrm{h})$ & 6.53 & 12.97 & 19.45 \\
\hline & $R^{2}$ & 0.9974 & 0.9606 & 0.9778 \\
\hline \multirow{4}{*}{$\begin{array}{l}\text { Type } 4 \text { pseudo-second-order: } \\
\qquad \frac{q_{t}}{t}=h_{2}-\frac{h_{2}}{q_{e}} q_{t}\end{array}$} & $q_{e, \exp }(\mathrm{mmol} / \mathrm{g})$ & 1.86 & 2.68 & 2.76 \\
\hline & $q_{e, c a l}(\mathrm{mmol} / \mathrm{g})$ & 1.97 & 2.90 & 2.92 \\
\hline & $k_{2}\left(\mathrm{~g}^{2} / \mathrm{mmol}^{2} \cdot \mathrm{h}\right)$ & 1.67 & 1.68 & 2.36 \\
\hline & $h_{2}(1 / \mathrm{h})$ & 6.52 & 14.13 & 20.12 \\
\hline \multirow{7}{*}{$\begin{array}{l}\text { Type } 5 \text { pseudo-second-order: } \\
\qquad \frac{1}{\left(q_{e}-q_{t}\right)}=\frac{1}{q_{e}}+k_{2} t\end{array}$} & $R^{2}$ & 0.9961 & 0.9488 & 0.9901 \\
\hline & $q_{e, \exp }(\mathrm{mmol} / \mathrm{g})$ & 0.86 & 2.68 & 2.76 \\
\hline & $k_{2}\left(\mathrm{~g}^{2} / \mathrm{mmol}^{2} \cdot \mathrm{h}\right)$ & 11.79 & 73.72 & 53.03 \\
\hline & $h_{2}(1 / \mathrm{h})$ & 40.57 & 529.02 & 403.73 \\
\hline & $R^{2}$ & 0.8639 & 0.8459 & 0.8092 \\
\hline & $q_{e, \exp }(\mathrm{mmol} / \mathrm{g})$ & 1.86 & 2.68 & 2.76 \\
\hline & $q_{e, c a l}(\mathrm{mmol} / \mathrm{g})$ & 2.03 & 2.93 & 2.84 \\
\hline \multirow{3}{*}{$\begin{array}{c}\text { Elovich } \\
q_{t}=\frac{1}{\beta} \ln (\alpha \beta)+\frac{1}{\beta} \ln t\end{array}$} & $\alpha(\mathrm{mmol} / \mathrm{g} \cdot \mathrm{h})$ & 16.68 & 71.32 & 96.25 \\
\hline & $\beta(\mathrm{g} / \mathrm{mmol})$ & 2.50 & 2.08 & 2.00 \\
\hline & $R^{2}$ & 0.9959 & 0.9277 & 0.9747 \\
\hline
\end{tabular}

the straight line through the origin, and $C$ is equal to zero. Meanwhile, the corresponding pore diffusion coefficient $\left(D_{p}, \mathrm{~cm}^{2} / \mathrm{min}\right)$ can be calculated, the calculating equation expression is: 


$$
k_{i d}=\frac{6 q_{e}}{r_{0}} \sqrt{\frac{D_{p}}{\pi}}
$$

where $r_{0}$ is the radius of particle, and the value is generally set to $0.05 \mathrm{~cm}$.

The graph between $q_{t}$ and $t^{0.5}$ at different initial concentrations about miglitol solution was plotted before reaching adsorption equilibrium. The results are shown in Figure 4. The parameters gotten by Webber-Morris equation fitting are presented in Table 2. It can be seen from Table 2 that the value of $C$ is not for zero, and just their values for $C$ increase with enhancing of solute concentration. It can make clear that the ion exchange process is not particle internal pore diffusion process, and further infer that the mass transfer process may be controlled by film diffusion or chemical reaction. Furthermore, the number of solute molecules for external layer of particle will increase with the augment of solute concentration, and then enhances mutual exclusive role for gay ions. It hinders migration of solute ions in the solution and leads to enlarge mass transfer resistance of the boundary layer, and the corresponding values $C$ will increase. In addition, the solute concentration in particle pore will increase with the initial concentration of miglitol during ion exchange process if the mass transfer process is controlled by internal pore diffusion. As known that internal pore diffusion resistance will increase because the adding the numbers of solute ions lead to enhance charge repulsive interaction in particle pore, the corresponding $D_{p}$ will decline.

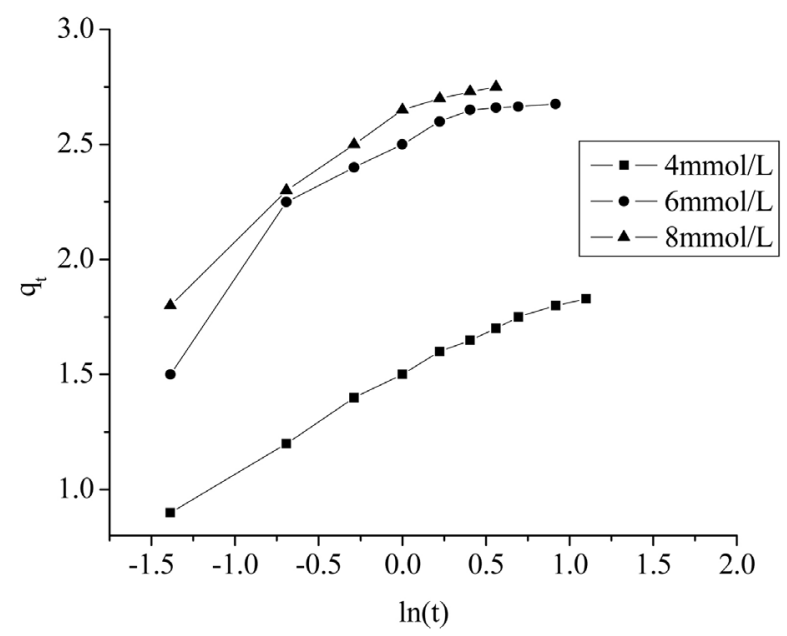

Figure 4. Fitting curves of the Elovich kinetic model for miglitol adsorbed onto D001 resin.

Table 2. Fitting parameters of the Webber-Morris kinetic model for miglitol adsorbed onto D001 resin.

\begin{tabular}{cccccc}
\hline$C_{0}(\mathrm{mmol} / \mathrm{L})$ & $\begin{array}{c}k_{i d} \\
\left(\mathrm{mmol} / \mathrm{g} \cdot \mathrm{min}^{0.5}\right)\end{array}$ & $r_{0}(\mathrm{~cm})$ & $\begin{array}{c}D_{p} \times 10^{6} \\
\left(\mathrm{~cm}^{2} / \mathrm{min}\right)\end{array}$ & $\begin{array}{c}C \\
(\mathrm{mmol} / \mathrm{g})\end{array}$ & $R^{2}$ \\
\hline 4 & 0.09 & 0.05 & 0.50 & 0.700 & 0.9546 \\
6 & 0.12 & 0.05 & 0.43 & 1.428 & 0.8545 \\
8 & 0.14 & 0.05 & 0.50 & 1.434 & 0.9333 \\
\hline
\end{tabular}


However, the calculating value $D_{p}$ in Table 2 is not the change trend of linear decline. It is mainly due to the internal diffusion coefficient greatly influenced by its own properties, and the homologous pore diffusion coefficients change a little. Therefore, it further proves that the adsorption process is not mainly controlled by internal pore diffusion.

Furthermore, the film diffusion coefficient can be calculated by film diffusion coefficient equation during ion exchange [26] [27] [28]. The equation is expressed as:

$$
D_{f}=0.23 \frac{r_{0} \delta}{t_{1 / 2}} \frac{\bar{C}}{C_{0}}
$$

where $D_{f}\left(\mathrm{~cm}^{2} / \mathrm{min}\right)$ is film diffusion coefficient, $\delta(\mathrm{cm})$ is a film thickness, the $\delta$ value is set to $10^{-3} \mathrm{~cm}$ for the spherical particle adsorbent. $t_{1 / 2}(\mathrm{~min})$ is the corresponding time for reaching halfway of adsorption capacity in the total ion exchange process. $\bar{C}$ is the solute quantity adsorbed by adsorbent particles. $C_{0}$ is an initial concentration for miglitol solution.

The experimental ion exchange was discussed by Type 1 pseudo-second order kinetic equation and film diffusion coefficient, the related parameters results are shown in Table 3. As known that the ion exchange process is controlled by film diffusion when the $D_{f}$ value is between from $10^{-6} \mathrm{~cm}^{2} / \mathrm{min}$ to $10^{-8} \mathrm{~cm}^{2} / \mathrm{min}$, the ion exchange process is regarded as pore diffusion control at $D_{p}$ value from $10^{-11} \mathrm{~cm}^{2} / \mathrm{min}$ to $10^{-13} \mathrm{~cm}^{2} / \mathrm{min}$ [29]. Combining with $D_{f}$ value at $10^{-6}$ to $10^{-8}$ $\mathrm{cm}^{2} /$ min in Table 3 and $D_{p}$ value in Table 2 and the diffusion coefficient magnitude corresponding with ion exchange process control principle, the ion exchange process at different concentrations for miglitol solution onto D001 resin is inferred as film diffusion control.

\subsection{Effect of Temperature}

The ion exchange process at different temperatures was investigated and the adsorption data gotten at the above experimental condition was analysed by the kinetic boundary model. The fitting result was obtained and the corresponding correlation coefficients were presented in Table 4. It is showed in Table 4 that there is a higher correlation coefficient for the ion exchange process fitted by film diffusion equation of the kinetic boundary, and the fitted curve is seen as in Figure 5, and makes clear that the ion exchange process is mainly controlled by film diffusion, the conclusion is consistent with the mass diffusion behavior gotten at different concentrations. However, the fitting correlation coefficients in Table 4

Table 3. Film diffusion coefficients for miglitol at different initial concentrations.

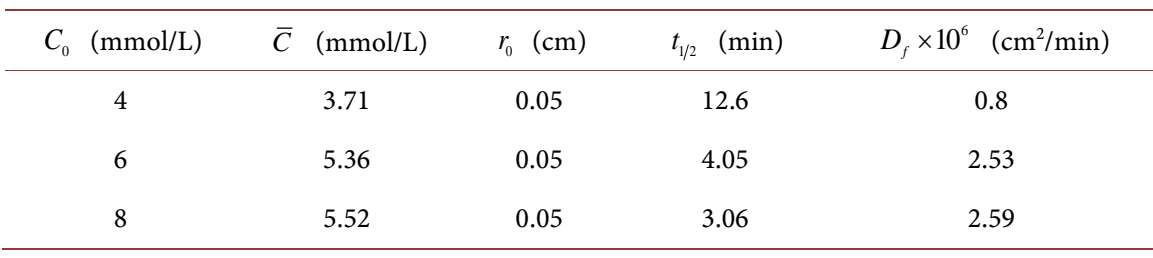


Table 4. Fitting correlation coefficients of the kinetic boundary model of miglitol adsorbed onto resin.

\begin{tabular}{cccc}
\hline \multirow{2}{*}{ Temperature } & \multicolumn{3}{c}{ Correlation coefficient $\left(\mathrm{R}^{2}\right)$} \\
\cline { 2 - 4 } & $-\ln (1-F)$ & $1-3(1-F)^{2 / 3}+2(1-F)$ & $1-(1-F)^{1 / 3}$ \\
\hline $30^{\circ} \mathrm{C}$ & 0.986 & 0.93 & 0.89 \\
$40^{\circ} \mathrm{C}$ & 0.97 & 0.92 & 0.898 \\
$50^{\circ} \mathrm{C}$ & 0.97 & 0.97 & 0.94 \\
\hline
\end{tabular}

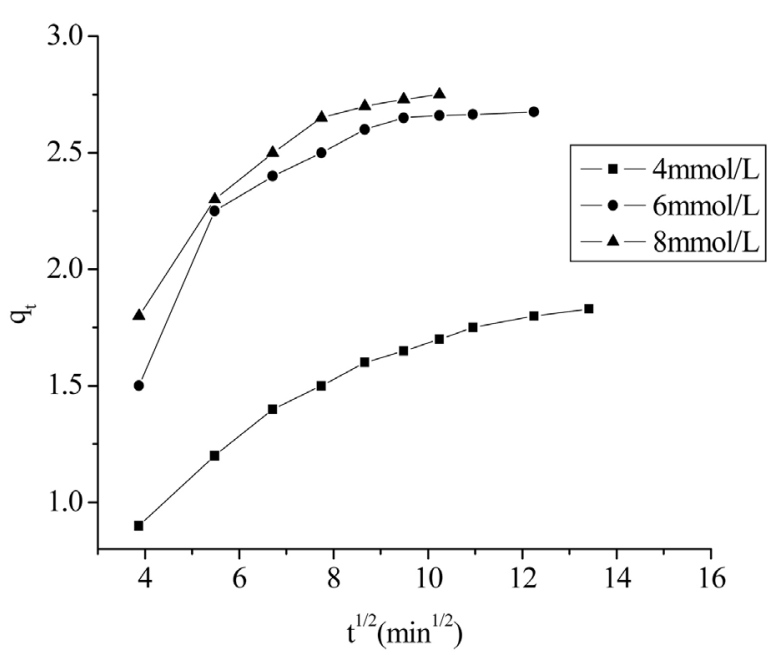

Figure 5. Plot of $t^{1 / 2}$ and $q_{\mathrm{t}}$ for miglitol at different initial concentrations.

for film diffusion and particle pore diffusion gradually come close each other with the increase experimental temperature. It can be concluded with increasing temperature that the mass transfer mechanism in ion exchange process is transferred gradually from film diffusion control to particle pore diffusion control. The main reason is that the mutual collision probability for solute molecules in particle pore and repulsion role of molecules each other all increase with the adding temperature, and hinders the external solute molecules to pass into the pore particle. The mass transfer resistance increases and leads to decrease for diffusion rate of solute molecules in particle pore. Therefore, the phenomenon in the whole ion exchange process emerges from film diffusion to the common control with particle pore diffusion and film diffusion.

In addition, the rate constant at different temperatures were obtained by the linear slope in Figure 5, and then the activation energy (Ea) can be calculated by Equation (20) and its value is $9.7 \mathrm{~kJ} / \mathrm{mol}$. Due to the activation energy of the ion exchange process is less than $16 \mathrm{~kJ} / \mathrm{mol}$, and it shows that the adsorption is controlled by the film diffusion. The conclusion is consistant with the gotten result from the kinetic boundary model. Meanwhile, the activation entropy change $\left(\Delta S^{*}\right)$ is counted for $-78.7 \mathrm{~J} / \mathrm{mol} \cdot \mathrm{K}$.

Moreover, the ion exchange process is analysed further by Type 1 pseudo-second order kinetic Equation (8) and the gotten drawing and the correspond- 
ing parameters are shown in Figure 6 and Table 5, respectively. It can be seen from Figure 6 and Table 5 that the curve between $t / q_{t}$ and $t$ is displayed the gradual increasing slope and has higher fitting degree by Equation (8) with the increase temperature. Their correlation coefficients reach over 0.99 , and it finds that the difference between the theory adsorption capacity for D001 resins $\left(q_{e, c a l}\right)$ and the gotten experimental value $\left(q_{e, \text { exp }}\right)$ is very small. This indicates that the Type 1 pseudo-second order kinetic equation can be used to describe the ion exchange process for miglitol onto D001 resin at different temperatures, and it is the same to the gotten results at different concentrations. The initial rate and the rate constant are all influenced obviously by experimental temperature. The initial rate $h_{2}$ declines apparently with the increase temperature and the rate constant reaches maximum at $40^{\circ} \mathrm{C}$. Meanwhile, the film diffusion constant is calculated by Equation (24) and shown in Table 6. It can be seen from Table 6 that the film diffusion coefficients decrease obviously with the increase temperature and are unfavorable to the mass transfer during ion exchange. Moreover, the calculated film diffusion coefficient consists in the range of $10^{-6}$ to $10^{-8} \mathrm{~cm}^{2} / \mathrm{min}$, and the ion exchange process is regarded as the film diffusion control, its inference is consistent with the gotten conclusion by the kinetic boundary model.

\subsection{Effect of Vibrating Rate}

The adsorption process at different vibrating rate was discussed and analysed by

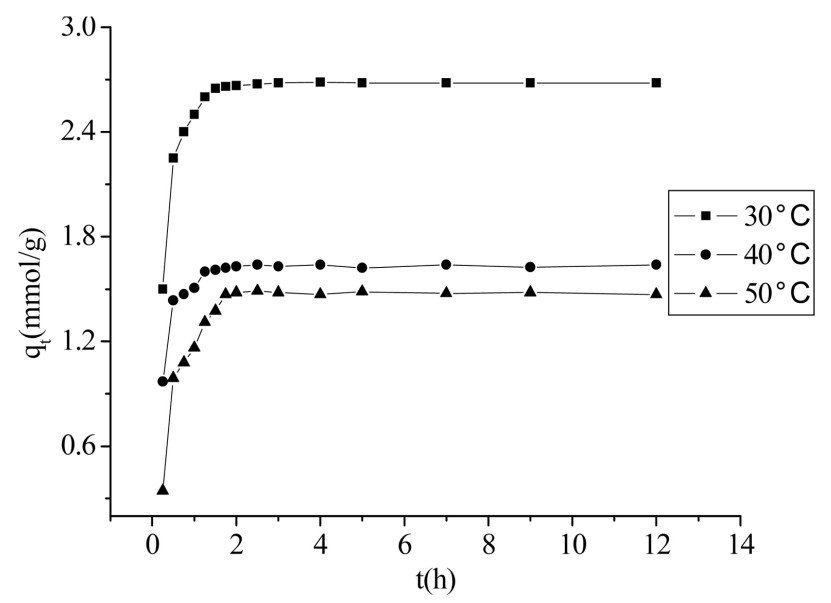

Figure 6. Effect of temperature on ion exchange process of miglitol adsorbed onto D001 resin.

Table 5. Fitting parameters of the pseudo-second-order kinetic model (Type 1) for miglitol adsorbed onto D001 resin.

\begin{tabular}{cccccc}
\hline $\begin{array}{c}\text { Temperature } \\
\left({ }^{\circ} \mathrm{C}\right)\end{array}$ & $q_{e, \text { cal }}(\mathrm{mmol} / \mathrm{g})$ & $\begin{array}{c}k_{2} \\
\left(\mathrm{~g}^{2} / \mathrm{mmol}^{2} \cdot \mathrm{h}\right)\end{array}$ & $h_{2}(1 / \mathrm{h})$ & $R^{2}$ & $q_{\text {eexp }}(\mathrm{mmol} / \mathrm{g})$ \\
\hline 30 & 2.70 & 5.49 & 40.00 & 0.9999 & 2.68 \\
40 & 1.65 & 9.69 & 26.30 & 0.9999 & 1.64 \\
50 & 1.52 & 2.80 & 6.49 & 0.9983 & 1.48 \\
\hline
\end{tabular}


Table 6. Film diffusion coefficients at different temperatures for miglitol adsorbed onto D001 resin.

\begin{tabular}{cccccc}
\hline $\begin{array}{c}\text { Temperature } \\
\left({ }^{\circ} \mathrm{C}\right)\end{array}$ & $\begin{array}{c}C_{0} \\
(\mathrm{mmol} / \mathrm{L})\end{array}$ & $\begin{array}{c}\bar{C} \\
(\mathrm{mmol} / \mathrm{L})\end{array}$ & $r_{0}(\mathrm{~cm})$ & $t_{1 / 2}(\mathrm{~min})$ & $\begin{array}{c}D_{f} \times 10^{6} \\
\left(\mathrm{~cm}^{2} / \mathrm{min}\right)\end{array}$ \\
\hline 30 & 6 & 5.36 & 0.05 & 4.05 & 2.53 \\
40 & 6 & 3.28 & 0.05 & 3.76 & 1.68 \\
50 & 6 & 2.96 & 0.05 & 14.00 & 0.40 \\
\hline
\end{tabular}

Type 1 pseudo-second order kinetic equation, the gotten process parameters were shown in Table 7. It is seen from Table 7 that their correlation coefficients all reach higher value and are over 0.99 , and it indicates that the ion exchange process at different stirring rates can be used to be described by Type 1 pseudo-second order kinetic equation. It is further analysed for Table 7 and found that the values of initial rate $h_{2}$ and rate constant $k_{2}$ all gradually increase with the boosting vibrating rate, and also affects mass transfer distinctly.

The film diffusion coefficient Equation (24) was used to calculate film diffusion coefficients in the experimental conditions, and was presented in Table 8. It is observed from Table 8 that the diffusion coefficients all present increase trend with the enhancing the vibrating rate, and the change trend is consistent with the above value changes of $k_{2}$ and $h_{2}$. At the same time, the calculated film diffusion coefficients is also existed in $10^{-6}$ and $10^{-8} \mathrm{~cm}^{2} / \mathrm{min}$, and the ion exchange process at different vibrating rates are regarded as film diffusion control too. The main reason is due to the selected adsorption resin D001 that belongs to a macroporous resin, and there is relatively weak adsorption resistance into the macroporous resin, ion exchange rate appears very fast and leads to complete the ion exchange very quickly within a very short time. The above a series of analysis can be concluded that the external adsorption factors such as solute concentration, temperature and vibrating rate for effect of mass transfer diffusion process control of miglitol onto D001 resin is relatively weak.

\section{Conclusion}

In the present work, a batch adsorption operation at the different influence factors for concentrations, temperatures and vibrating rate in the constant temperature bath oscillator (SHZ-A) has been performed for miglitol adsorption by resin D001. The experimental results showed that Type 1 pseudo-second order kinetic equation can be all used to describe miglitol adsorbed by D001 resin at different concentrations, temperatures and vibrating rates. Moreover, Webber-Morris kinetic equation, film diffusion coefficient equation and kinetic boundary model were also applied to discuss the adsorption process, and then calculated values of the process film diffusion coefficient and pore diffusion coefficient, the total activation energy $\left(E_{a}\right)$ can be calculated and its value is $9.7 \mathrm{~kJ} / \mathrm{mol}$. The ion exchange process is all mainly controlled by film diffusion. The external adsorption factors such as solute concentration, temperature and vibrating rate for effect of mass 
Table 7. Fitting parameters of the Type-1 pseudo-second-order kinetic model for miglitol adsorbed onto resin D001.

\begin{tabular}{cccccc}
\hline $\begin{array}{c}\text { Vibrating rate } \\
(\mathrm{rmp})\end{array}$ & $\begin{array}{c}q_{e, \text { cal }} \\
(\mathrm{mmol} / \mathrm{g})\end{array}$ & $\begin{array}{c}k_{2} \\
\left(\mathrm{~g}^{2} / \mathrm{mmol}^{2} \cdot \mathrm{h}\right)\end{array}$ & $h_{2}(1 / \mathrm{h})$ & $R^{2}$ & $\begin{array}{c}q_{e, \exp } \\
(\mathrm{mmol} / \mathrm{g})\end{array}$ \\
\hline 80 & 2.94 & 0.39 & 3.4 & 0.9963 & 2.68 \\
120 & 2.70 & 5.49 & 40.0 & 0.9999 & 2.68 \\
160 & 2.70 & 5.97 & 43.5 & 0.9999 & 2.68 \\
\hline
\end{tabular}

Table 8. Film diffusion coefficients at different vibrating rates.

\begin{tabular}{cccccc}
\hline $\begin{array}{c}\text { Vibrating rate } \\
(\mathrm{rmp})\end{array}$ & $\begin{array}{c}C_{0} \\
(\mathrm{mmol} / \mathrm{L})\end{array}$ & $\bar{C}(\mathrm{~mol} / \mathrm{L})$ & $\begin{array}{c}r_{0} \\
(\mathrm{~cm})\end{array}$ & $t_{1 / 2}(\mathrm{~min})$ & $\begin{array}{c}D_{f} \times 10^{6} \\
\left(\mathrm{~cm}^{2} / \mathrm{min}\right)\end{array}$ \\
\hline 80 & 6 & 5.36 & 0.05 & 51.16 & 0.20 \\
120 & 6 & 5.36 & 0.05 & 4.05 & 2.53 \\
160 & 6 & 5.36 & 0.05 & 3.73 & 2.74 \\
\hline
\end{tabular}

transfer diffusion process control of miglitol onto D001 resin is relatively weak.

\section{Acknowledgements}

We acknowledge the financial supports from the special fund of education department of Shaanxi province (16JK1510) and the nurturing fund projects of Xi'an University of Science and Technology (2014022) in China.

\section{References}

[1] Kinast, G., Koebernick, W. and Schedel, M. (1982) Process for the Preparation of N-Substituted Derivatives of 1-Desoxynojirimycin. EP0049858.

[2] Scott, L.J. and Spencer, C.M. (2000) Miglitol. Drugs, 59, 521-549. https://doi.org/10.2165/00003495-200059030-00012

[3] JE Sels, J.-P., SP Huijberts, M. and HR Wolffenbuttel, B. (1999) Miglitol, a New $\alpha$-Glucosidase Inhibitor. Miscellaneous, 1, 149-156.

[4] Schedel, M., Rehm, H.-J. and Reed, G. (2008) Regioselective Oxidation of Aminosorbitol with Gluconobacter Oxydans, Key Reaction in the Industrial 1-Deoxynojirimycin Synthesis. Biotechnology: Biotransformations II, Second Edition, 8B, Wiley-vch.de, Wuppertal Germany, 295-311.

[5] Zhang, X., Wu, B., Wang, B., et al. (2011) Facile and Stereo-Controlled Synthesis of 2-Deoxynojirimycin, Miglustat and Miglitol. Tetrahedron Letters, 52, 3802-3804. https://doi.org/10.1016/j.tetlet.2011.05.063

[6] Grabner, R.W., Landis, B.H., Wang, P.T., et al. (1996) Process for Producing N-Substituted-1-Deoxynojirimycin. EP0477160.

[7] Roy, A., Achari, B. and Mandal, S.B. (2006) A Short and Simple Synthesis of 1-Deoxynojirimycin Derivatives from D-Glucose. Synthesis, 31, 1035-1039.

[8] Takahata, H., Banba, Y., Sasatani, M., et al. (2004) Asymmetric Synthesis of 1-Deoxynojirimycin and Its Congeners from a Common Chiral Building Block. Tetrahedron, 60, 8199-8205. https://doi.org/10.1016/j.tet.2004.06.112

[9] Blunk, D., Praefcke, K. and Legler, G. (1994) A New Family of Carbohydrate Liquid 
Crystals. N-Alkylated 1-Deoxynojirimycin Derivatives. Liquid Crystals, 17, 841-846. https://doi.org/10.1080/02678299408035476

[10] Grabner, R.W., Landis, B.H., Wang, P.T. and Prunier, M.L. (1995) Process for Producing N-Substituted-1-Deoxynojirimycin. UP585588.

[11] Zhang, J., Zhang, X., Li, H., et al. (2012) Ion Exchange Adsorption Studies of Miglitol in a Fixed Bed. Chemical Engineering \& Technology, 35, 811-818. https://doi.org/10.1002/ceat.201100685

[12] Ibrahim, F.A., Ali, F.A., Ahmed, S.M., et al. (2007) Kinetic Determination of Acarbose and Miglitol in Bulk and Pharmaceutical Formulations using Alkaline Potassium Permanganate. International Journal of Biomedical Science, 1, 20-30.

[13] Lagergren, S. (1898) About the Theory of So-Called Adsorption of Soluble Substances. Kungliga Svenska Vetenskapsakademiens. Handlingar, Band, Vol. 24, 1-39.

[14] Shek, T.-H., Ma, A., Lee, V.K.C., et al. (2009) Kinetics of Zinc Ions Removal from Effluents using Ion Exchange Resin. Chemical Engineering Journal, 146, 63-70.

[15] Hameeda, B.H. and El-Khaiary, M.I. (2008) Malachite Green Adsorption by Rattan Sawdust: Isotherm, Kinetic and Mechanism Modeling. Journal of Hazardous Materials, 159, 574-579.

[16] Ho, Y.S. and McKay, G. (1999) The Sorption of Lead (II) Ions on Peat. Water Research, 33, 578-584.

[17] Ho, Y.S. and McKay, G. (2000) The Kinetics of Sorption of Divalent Metal Ions onto Sphagnum Moss Flat. Water Research, 34, 735-742.

[18] Low, M.J.D. (1960) Kinetics of Chemisorption of Gases on Solids. Chemical Reviews, 60, 267-312. https://doi.org/10.1021/cr60205a003

[19] Helffrich, F. (1962) Ion Exchange. McGraw-Hill, New York, 324-326.

[20] Tsou, H.S. and Graham, E.E. (1985) Prediction of Adsorption and Desorption of Protein on Dextran Based Ion-Exchange Resin. AIChE Journal, 31, 1959-1966.

[21] Nibou, D., Mekatel, H., Amokrane, S., et al. (2010) Adsorption of $\mathrm{Zn}^{2+}$ Ions onto $\mathrm{NaA}$ and NaX Zeolites: Kinetic, Equilibrium and Thermodynamic Studies. Journal of Hazardous Materials, 173, 637-646.

[22] Anirudhan, T.S., Divya, L. and Suchithra, P.S. (2009) Kinetic and Equilibrium Characterization of Uranium (IV) Adsorption onto Carboxylate-Fnctionalized Poly (Hydroxyethylmethacrylate)-Grafted Lignocellulosics. Journal of Environmental Management, 90, 549-560.

[23] Mittal, A., Mittal, J. and Kurup, L. (2006) Adsorption Isotherms, Kinetics and Column Operations for the Removal of Hazardous Dye, Tartrazine from Aqueous Solutions using Waste Materials-Bottom Ash and De-Oiled Soya, as Adsorbents. Journal of Hazardous Materials B, 136, 567-578.

[24] Ahmed, E.N. (2009) Potential of Pomegranate Husk Carbon for Cr (VI) Removal from Wastewater: Kinetic and Isotherm Studies. Journal of Hazardous Materials, 161, 132-141.

[25] Sabir, H., Hamidi, A.A., Mohamed, H.I., et al. (2006) Physico-Chemical Method for Ammonia Removal from Synthetic Wastewater using Limestone and GAC in Batch and Column Studies. Bioresource Technology, 98, 874-880.

[26] Anirudhan, T.S. and Ramachandran, M. (2006) Adsorptive Removal of Tannin from Aqueous Solutions by Cationic Surfactant-Modified Bentonite Clay. Journal of Colloid Interface Science, 299, 116-124.

[27] Rengaraj, S., Kyeong-Ho, Y. and Seung-Hyeon, M. (2001) Removal of Chromium 
from Water and Wastewater by Ion Exchange Resins. Journal of Hazardous Materials, 87, 273-287.

[28] Mehmet, E.A. (2008) Use of Clinptilolite for the Removal of Nickel Ions from Water: Kinetics and Thermodynamics. Journal of Hazardous Materials, 150, 587-595.

[29] Michelson, L.D., Gideon, P.G., Pace, E.G., et al. (1975) Removal of Soluble Mercury from Wastewater by Complexing Technique. US Department of Industry, Office of Water Research and Technology, Bulletin No. 74. 
Nomenclature

\begin{tabular}{|c|c|c|}
\hline$q_{t}$ & {$[\mathrm{mmol} / \mathrm{g}]$} & adsorption capacity of resin at time $t$ \\
\hline$C_{0}$ & {$[\mathrm{mmol} / \mathrm{L}]$} & initial concentration \\
\hline$V_{0}$ & {$[\mathrm{~L}]$} & initial solution volume \\
\hline$C_{n}$ & {$[\mathrm{mmol} / \mathrm{L}]$} & remaining solution concentration \\
\hline$V_{n}$ & {$[\mathrm{~L}]$} & remaining volume \\
\hline$C_{i}$ & {$[\mathrm{mmol} / \mathrm{L}]$} & taken solution sample concentration \\
\hline$V_{i}$ & {$[\mathrm{~L}]$} & taken solution sample volume \\
\hline$W$ & {$[\mathrm{~g}]$} & resin weight \\
\hline$q_{e}$ & {$[\mathrm{mmol} / \mathrm{g}]$} & $\begin{array}{l}\text { equilibrium adsorption capacity for } \\
\text { adsorbent }\end{array}$ \\
\hline$q_{t}$ & {$[\mathrm{mmol} / \mathrm{g}]$} & adsorption capacity for adsorbent at time $t$ \\
\hline$k_{1}$ & {$[\mathrm{~g} / \mathrm{mmol} \cdot \mathrm{h}]$} & rate constant for the Lagergren equation \\
\hline$k_{2}$ & {$\left[\mathrm{~g}^{2} / \mathrm{mmol}^{2} \cdot \mathrm{h}\right]$} & $\begin{array}{l}\text { rate constant for the pseudo-second order } \\
\text { equation }\end{array}$ \\
\hline$h_{1}$ & {$[1 / \mathrm{h}]$} & initial rate of pseudo-first order equation \\
\hline$h_{2}$ & {$[1 / \mathrm{h}]$} & initial rate of pseudo-second order equation \\
\hline$\alpha$ & {$[\mathrm{mmol} / \mathrm{g} \cdot \mathrm{h}]$} & initial adsorption rate of Elovish equation \\
\hline$\beta$ & {$[\mathrm{g} / \mathrm{mmol}]$} & desorption constant \\
\hline$F$ & [\%] & ion exchange degree \\
\hline$R^{2}$ & & correlation coefficient \\
\hline$E_{a}$ & {$[\mathrm{~kJ} / \mathrm{mol}]$} & activation energy \\
\hline$\Delta S^{*}$ & {$[\mathrm{~J} / \mathrm{mol} \cdot \mathrm{K}]$} & activation entropy change \\
\hline$K$ & {$[\mathrm{~J} / \mathrm{K}]$} & Boltzmann constant \\
\hline$h$ & & Plank constant \\
\hline$k_{i d}$ & {$\left[\mathrm{mmol} / \mathrm{g} \cdot \mathrm{min}^{0.5}\right]$} & internal diffusion rate constant \\
\hline$C$ & & intercept \\
\hline$r_{0}$ & {$[\mathrm{~cm}]$} & particle radius \\
\hline$D_{p}$ & {$\left[\mathrm{~cm}^{2} / \mathrm{min}\right]$} & pore diffusion coefficient \\
\hline$D_{f}$ & {$\left[\mathrm{~cm}^{2} / \mathrm{min}\right]$} & film diffusion coefficient \\
\hline$\delta$ & {$[\mathrm{cm}]$} & film thickness \\
\hline$t_{1 / 2}$ & {$[\mathrm{~min}]$} & $\begin{array}{l}\text { time for reaching halfway of adsorption } \\
\text { capacity }\end{array}$ \\
\hline $\bar{C}$ & {$[\mathrm{mmol} / \mathrm{L}]$} & $\begin{array}{l}\text { solute quantity adsorbed by adsorbent } \\
\text { particles }\end{array}$ \\
\hline \multicolumn{3}{|c|}{ Subscripts } \\
\hline $\mathrm{cal}$ & calculated & \\
\hline $\exp$ & experimental & \\
\hline
\end{tabular}

